\title{
$\angle$ Research Square

\section{Remote Work and the Environment: Exploratory Analysis of Indoor Air Quality of Commercial Offices and the Home Office}

\section{Kamrie Sarnosky}

Texas A\&M Health Science Center

Mark Benden

Texas A\&M Health Science Center

\section{Leslie Cizmas}

Texas A\&M Health Science Center

Annette Regan

University of San Francisco

Garett Sansom ( $\nabla$ sansom@tamu.edu )

Texas A\&M Health Science Center

\section{Research Article}

Keywords: home office, indoor air quality, remote work, COVID-19

Posted Date: February 5th, 2021

DOI: https://doi.org/10.21203/rs.3.rs-146008/v1

License: (c) (1) This work is licensed under a Creative Commons Attribution 4.0 International License. Read Full License 


\section{Abstract}

Background: The COVID-19 pandemic has accelerated an already existing trend of individuals increasingly working remotely. With the growing popularity of remote working, specifically in a home office, there is a critical need to better understand and characterize the potential environmental differences between these two spaces. Indoor air pollution can have adverse health effects and impair cognitive functioning.

Methods: This small pilot cohort study $(\mathrm{N}=22)$ recruited home and office workers to better understand the indoor air quality between these spaces. Air contaminants collected and assessed included $\mathrm{PM}_{10}$ and $\mathrm{PM}_{2.5}$, carbon dioxide (CO2), and total volatile organic compounds (TVOCs).

Results: Findings showed a strong statistically significant increase in all measured variables within homes in comparison to traditional offices $(p<0.001)$. For instance, The mean PM2.5 level in the traditional office space was $1.93 \mu \mathrm{g} / \mathrm{m} 3$ whereas it was more than twice this amount $(5.97 \mu \mathrm{g} / \mathrm{m} 3)$ in home offices.

Conclusion: These results indicate that those who work from home are at increased risk due to longer exposures to higher levels of certain contaminants, the importance to better develop interventions to mitigate this reality is underscored by the fact that many workers will be moving to home-based offices in the coming years.

\section{Introduction}

Within the United States, adults spend roughly 90 percent of their day indoors, an amount that has been on the rise for several generations $[1,2]$. This reality places populations in continuous exposure to certain complex mixtures of chemicals and contaminants associated with indoor air quality. This is underscored by the fact that across business sectors and industries, employees are increasingly being given the opportunity to work from home. Prior to the COVID-19 pandemic, according to the Bureau of Labor and Statistics, over a third of individuals in professional and management, business, or financial operations performed some or all of their main job in their residence [3]. While traditionally an adult worker would spend some of their day in an office building and some of their day in their home, the shift to a remote workforce keeps employees in the same microenvironment for more time. Further, due to the COVID-19 pandemic, many employers are increasing the types of work that can be done from home, and preliminary evidence suggests that both workers and employers enjoy the flexibility of working remotely and many positions will continue to remain remote even after the risks associated with the pandemic have passed [4].

With the increasing popularity of remote working, specifically in a home office, there is a critical need to better understand and characterize the potential environmental differences between these two spaces. Research has explored the air quality within offices and workspaces for some decades, often identifying potential health risks and offering suggestion for mitigating these exposures [5]. Due to the differences in 
maintenance responsibilities and available guidelines in commercial office buildings and residential homes, we hypothesized that individuals in the U.S. may be exposed to higher concentrations of pollutants in the home than in a traditional office environment, where there are initiatives to keep indoor air pollutants as low as possible.

Research has produced strong evidence that exposure to certain ambient compounds can cause negatve health outcomes. For instance, particular matter (PM) is related to acute and chronic bronchitis, asthma diagnosis, diagnosis of several additional health conditions including cardiopulmonary disorders and even increased mortality of the exposed [6-8]. This is particularly true with $\mathrm{PM}_{10}$ (particulate matter 10 micrometers or less in diameter) and $\mathrm{PM}_{2.5}$ (particulate matter 2.5 micrometers or less in diameter) [9].

The objective of this study was to explore and determine the difference in air composition between office workspaces provided by employers (traditional office) and the home office. While the exact composition of indoor air is complex and highly variable, this pilot cohort study assessed select pollutants that have been associated with sick building syndrome and other adverse health effects to generate findings in an attempt to bridge this critical knowledge gap.

\section{Methods}

\subsection{Recruitment}

This cohort study consisted of a sample of traditional office employees and a sample of individuals who work primarily from a space within their residence. The traditional office cohort, or work space that is managed by an employer, was recruited from the Texas A\&M Health Science Center in College Station, TX (HSC). A recruitment email was sent to all employees of the Texas A\&M Health Science Center and members of the Bryan-College Station Chamber of Commerce from March 2019 through May 2019. To reach the target sample size for the home worker cohort, recruitment emails were also sent to individuals who were referred by other participants and alumni of the Texas A\&M Health Science Center (HSC).

Traditional office cohort participants were eligible to participate if they worked in their office space at the HSC for the majority (>50\%) of their work week. No other exclusion criteria were applied. All HSC employees were considered traditional office space employees and had a designated work space in a building of Texas A\&M University or a university-affiliated medical care facility in College Station, TX, Round Rock, TX, or Lake Jackson, TX in eh United States. Each office included a traditional seated desk, a computer, and a computer task chair. All traditional office employees had access to traditional meeting rooms, a kitchen-area, and community-style restrooms on the floor of their office.

Participants were asked to complete a survey and allow an air quality monitor to run in their home from Monday through Friday of a work week. Participants were compensated $\$ 100$ for participating. This study took place over an eight-week period from April 15, 2019 - June 14, 2019. Ethical guidance and 
approval was obtained from the Texas A\&M University Institutional Review Board (IRB2018-0617D) and written consent was obtained from all participants.

\subsection{Indoor Air Quality Monitoring}

Air monitoring was accomplished through the utilization of the ParticlesPlus 7302 Air Quality and Environmental Monitoring device (ParticlesPlus, Stoughton, MA, USA). The ParticlesPlus 7302 Environmental Monitor measures particles between 0.3-25 $\mu \mathrm{m}$ and contains a nondispersive infrared (DNIR) $\mathrm{CO}_{2}$ sensor that allows for a reading of up to $5000 \mathrm{ppm}$. The monitor also contains photo ionization sensor (PID) that will respond to volatile organic compounds between 0-50 ppm.

Measurements of $\mathrm{PM}_{10}$ and $\mathrm{PM}_{2.5}$ were collected due to their clinical relevance [10-12] and established presence in residential spaces $[13,14]$. Further, measurements of total volatile organic compounds (TVOCs) were collected as many individual volatile organic compounds have been determined to be carcinogenic by the Environmental Protection Agency (EPA) and the International Agency for Research on Cancer $[15,16]$. Levels of carbon dioxide $\left(\mathrm{CO}_{2}\right)$ was likewise collected due to it's, and VOCs, association with lower cognitive scores in the workplace [17].

The monitor was placed in a representative location of the area that the participant reported spending the majority of their time working. Care was taken not to place the monitor in direct sunlight or near open flames. Typically, the monitor was placed on a side table or on top of a shelf near a desk or primary workspace. The monitor was set to take a one-minute sample every fifteen minutes continuously from Monday to Friday of the participants' work week. The air sampling flow rate was 0.1 cubic feet per minute (CFM). Monitors were calibrated according to the manufacturer's instructions between every other sampling period.

The office workers recruited from this study were all employed by the Texas A\&M University Health Science Center. The Texas A\&M Health Science Center consists of several office buildings - this study was performed at the HSC buildings in College Station, TX. The buildings are maintained by a facilities services team, who ensure that the building has new minimum efficiency reporting value- 11 (MREV-11) air filters monthly. The conditioning and maintenance of indoor air of the home offices were unknown prior to this study.

\subsection{Analysis}

Statistical analysis was performed using STATA/IC 15.1 (College Station, TX). Survey data was used to describe participant demographics and select consumer products or other known sources of pollutants that may be found in the residential space. Mondays and Fridays were cut from the dataset to create a midweek snapshot of the participant's work environment. Midweek data was used to allow for equipment pick up/ drop off time. Means, medians, and ranges were calculated for each parameter and each cohort. A repeated measures ANOVA was performed for each parameter $(a=0.05)$. Non-parametric data $\left(P_{2.5}\right.$, $\mathrm{PM}_{10}, \mathrm{CO}_{2}$ \& TVOCs) were log transformed prior to performing the ANOVA. 


\section{Results}

\subsection{Participants}

A total of 22 individuals were recruited for this study $(\mathrm{N}=22)$. The demographics of the home and office workers included in this study are presented in Table 1. The home worker cohort consisted of white individuals $(n=11)$, ranging from 35-61 $(\mu=45.9)$ years. The office cohort was less homogenous, with more diversity in race and an age ranged of $23-55(\mu=35.9)$ years. All study participants were employed in computer-based jobs, such as university faculty positions and administrative assistants. The home worker cohort was employed in jobs including business owner, sales representative and ergonomists. All home workers lived in single-family dwellings in Central or South Texas. 
Table 1

Sample Characteristics

\begin{tabular}{|c|c|c|}
\hline & $\begin{array}{l}\text { Home } \\
N=11 n(\%)\end{array}$ & $\begin{array}{l}\text { Office } \\
N=11 \text { n(\%) }\end{array}$ \\
\hline \multicolumn{3}{|l|}{ Gender } \\
\hline Male & $6(54.5)$ & $3(27.27)$ \\
\hline Female & $5(45.5)$ & $8(72.73)$ \\
\hline \multicolumn{3}{|l|}{ Age } \\
\hline Mean (Range) & $45.9(35-61)$ & $35.9(23-55)$ \\
\hline \multicolumn{3}{|l|}{ Race } \\
\hline White & 11(100) & $7(63.64)$ \\
\hline Asian & 0 & $1(9.09)$ \\
\hline Hispanic & 0 & $2(18.18)$ \\
\hline Hawaiian & 0 & $1(9.09)$ \\
\hline \multicolumn{3}{|c|}{ Highest Level of Educational Attainment } \\
\hline High school degree & $1(9)$ & $1(9.09)$ \\
\hline Undergraduate & $5(45.5)$ & $6(54.55)$ \\
\hline Postgraduate & $5(45.5)$ & $4(36.36)$ \\
\hline \multicolumn{3}{|l|}{ Household Income } \\
\hline Less than $\$ 50,000$ & 0 & $3(27.27)$ \\
\hline$\$ 50,000-\$ 75,000$ & $2(18.18)$ & $3(27.27)$ \\
\hline$\$ 100,000-\$ 150,000$ & $1(9)$ & $3(27.27)$ \\
\hline Greater than $\$ 150,000$ & $7(63.50)$ & $2(18.18)$ \\
\hline Refuse to answer & $1(9)$ & 0 \\
\hline \multicolumn{3}{|c|}{ Time Spent at Workstation (Hours/day) } \\
\hline$\leq 5$ & $4(36.36)$ & $2(18.18)$ \\
\hline $6-7$ & $5(45.45)$ & 8 (72.73) \\
\hline$>8$ & 2 (18.18) & 1 (9.09) \\
\hline
\end{tabular}


The mean, median, range and ANOVA results are presented in Table 2.

$\mathrm{PM}_{2.5}$ and $\mathrm{PM}_{10}$ levels were significantly higher in private residential spaces than in the traditional commercial office buildings $(\mathrm{p}<0.0001)$. The average $\mathrm{PM}_{2.5}$ level in the traditional office space was 1.93 $\mu \mathrm{g} / \mathrm{m}^{3}$ and the average level in the home office space was more than double that amount $\left(5.97 \mu \mathrm{g} / \mathrm{m}^{3}\right)$. Additionally, average $\mathrm{PM}_{10}$ level in the traditional office space was $7.57 \mu \mathrm{g} / \mathrm{m}^{3}$, whereas, the home office space was $16.37 \mu \mathrm{g} / \mathrm{m}^{3}(\mathrm{p}<0.0001)$. TVOCs were significantly higher in the home than the traditional office $(p<0.0001)$. While the TVOCs in the office were not consistently detected $(\mu=53.04 \mathrm{ppb}$, median $=$ $1 \mathrm{ppb})$, the average in the home office space was four times as high $(213.00$, median $=154.00)$. 
Table 2

Comparison (ANOVA) of air quality measures within traditional office spaces and home offices

\begin{tabular}{|c|c|c|c|}
\hline & Traditional Office & Home Office & p-value \\
\hline \multicolumn{4}{|c|}{$\mathrm{PM}_{2.5}\left(\mu \mathrm{g} / \mathrm{m}^{3}\right)$} \\
\hline Mean & 1.93 & 5.97 & $p<0.0001$ \\
\hline Median & 1.24 & 2.68 & \\
\hline Min & 0.15 & 0.38 & \\
\hline Max & 119.90 & 307.74 & \\
\hline \multicolumn{4}{|c|}{$\mathrm{PM}_{10}\left(\mu \mathrm{g} / \mathrm{m}^{3}\right)$} \\
\hline Mean & 7.47 & 16.37 & $p<0.0001$ \\
\hline Median & 3.27 & 8.15 & \\
\hline Min & 0.17 & 0.48 & \\
\hline Max & 345.07 & 830.57 & \\
\hline \multicolumn{4}{|c|}{ TVOCs (ppb) } \\
\hline Mean & 53.04 & 213.00 & $p<0.0001$ \\
\hline Median & 51.00 & 154.00 & \\
\hline Min & 0 & 0 & \\
\hline Max & 2395 & 620 & \\
\hline \multicolumn{4}{|c|}{$\mathrm{CO}_{2}(\mathrm{ppm})$} \\
\hline Mean & 432.07 & 370 & $p<0.0001$ \\
\hline Median & 415 & 696 & \\
\hline Min & 330 & 370 & \\
\hline Max & 763 & 2309 & \\
\hline
\end{tabular}

While all pollutant levels tended to be higher in the home, the levels of each pollutant were not consistent throughout the sample period and experienced peaks throughout the day. There was also noticeable variability of results within the home offices in comparison to traditional office locations (Fig. 1).

Levels of TVOC were consistently higher within home residence compared to traditional offices. These levels remained stable throughout the study period and reveals significantly higher levels in home workers. With the exception of one dramatic outlier, there was no time that traditional offices had increased levels (Fig. 2). 


\subsection{Ethical statement}

Ethical guidance and approval was obtained from the Texas A\&M University Institutional Review Board (IRB2018-0617D). Written informed consent was obtained from all participants. This research was conducted in accordance to the Declaration of Helsinki

\section{Discussion}

This exploratory study found a statistically significant difference in the indoor air quality in home offices and traditional office spaces for all monitored variables. Results are consistent with a previous study that suggested VOC levels were higher in the home environment than the office environment [18]. Though there were some spikes throughout the sampling period, we found that the traditional office space had consistently lower TVOCs than the home office. With the equipment used, it is not possible to identify which particular VOCs were present or the source of the pollutant. While there are some known risk levels published by government agencies, such as the Agency for Toxic Substance and Disease Registry's (ATSDR) minimal risk levels for many individual VOCs, these levels tend to be focused on high levels of acute exposure [19], they do not account for low levels of exposure over long periods of time.

The levels of $\mathrm{CO}_{2}$ were also statistically higher in the home than in the traditional offices in this study. Previous studies have shown the association between high $\mathrm{CO}_{2}$ and Sick Building Syndrome and other adverse effects [14]. In a 2012 study by Tsai et al [20], generalized estimated equation models showed that workers exposed to $\mathrm{CO}_{2}$ of $800 \mathrm{ppm}$ were more likely to report eye irritation or upper respiratory symptoms. Here, we found levels in the home average about 800 ppm at several points during the sampling period and, in some cases, individual readings over 2000 ppm.

This study presents a variety of limitations. The population sample was homogenous, with all participants above the poverty line and, at minimum, a high school education. All air quality samples were taken in south Texas during the spring and may not be generalizable to other regions. The air quality results presented here are three-day snapshots of the chemical make-up of indoor air in a small sample of homes and office spaces. The office spaces included in this study are located in buildings at a major university and may not be consistent with other commercial building spaces. Future studies should consider the fluctuation of pollutants seasonally throughout the year. Further, it is important to make the distinction that the presence of a pollutant is not synonymous with individual exposure.

We found consistently higher levels of pollutants in the home environment than the office environment. Due to the complexity of the makeup of air, it is difficult to determine if any of the pollutants are clinically significant. However, some of the pollutants monitored in this study exceeded health-based standards and recommendations. While this study did not investigate the sources of the pollutants or the outdoor air exchange rate within the homes, future studies should consider these factors in order to help remote 
employees reduce the risk of potential adverse health effects of poor indoor air quality. Some pollutants were not comparable to certain standards due to differences in measurement units. This makes determining action levels for pollutants difficult. If recommendations of pollutant levels in residential spaces are created, care should be taken to harmonize reporting units

\section{Conclusion}

Traditionally, working adults would split their time between a home and office microenvironment. However, the transition of the workforce from a commercial office building to a home-based office results in more time in the residential microenvironment. This potentially increases the long-term exposure to pollutants found in the homes. The importance of discovering the environmental conditions within homes is exacerbated by the reality that any positions are planned to permanently move out of traditional offices and within homes. This exploratory study showed a statistically significant difference in the chemical make-up of air in residential and office space with the more favorable results appearing in the commercial office spaces. Guidance for acceptable levels of pollutants in homes should be established to enable home office employees to minimize their long-term exposure to pollutants.

\section{Declarations}

\section{Ethics approval and consent to participate:}

Ethical guidance and approval was obtained from the Texas A\&M University Institutional Review Board (IRB2018-0617D). Written informed consent was obtained from all participants. This research was conducted in accordance to the Declaration of Helsinki

\section{Author Contributions:}

Authors listed in this article have made several contributions to this research, in detail: Conceptualization, KS and MB Methodology KS, MB, AR. Software, KS Validation, KS, MB Formal analysis, KS Investigation, $\mathrm{KS}, \mathrm{MB}, \mathrm{AR}$, GS LC. Writing-original draft, KS Writing-review and editing, GS, MB

\section{Funding:}

This research received no external funding

\section{Consent for Publication:}

Not Applicable 


\section{Data Availability Statement:}

All reasonable requests for data will be honored. Primary contact is Garett Sansom sansom@tamu.edu

\section{Conflicts of Interest:}

The authors declare no conflict of interest.

\section{References}

1. Dales, R., Liu, L., Wheeler, A. J., \& Gilbert, N. L. (2008). Quality of indoor residential air and health. CMAJ, 179(2), 147-152.

2. Bernstein, J. A., Alexis, N., Bacchus, H., Bernstein, L., Fritz, P., Homer, E., .. Tarlo, S. M. (2008). The health effects of nonindustrial indoor air pollution. Journal of Allergy and Clinical Immunology, 121(3), 585-591.

3. Bureau of Labor Statistics, U.S. Department of Labor. (2015). 24 percent of employed people did some or all of their work at home in 2015. Retrieved November 2018, from The Economics Daily: https://www.bls.gov/opub/ted/2016/24-percent-of-employed-people-did-some-or-all-of-their-work-athome-in-2015.htm

4. Béland, L. P., Brodeur, A., \& Wright, T. (2020). The short-term economic consequences of Covid-19: exposure to disease, remote work and government response.

5. Gomzi, M., \& Bobić, J. (2009). SICK BUILDING SYNDROME Do we live and work in unhealthy environment?. Periodicum biologorum, 111(1), 79-84.

6. Chi, R., Chen, C., Li, H., Pan, L., Zhao, B., Deng, F., \& Guo, X. (2019). Different health effects of indoorand outdoor-originated PM2. 5 on cardiopulmonary function in COPD patients and healthy elderly adults. Indoor air, 29(2), 192-201.

7. Dehbi HM, Blangiardo M, Gulliver J, et al. Air pollution and cardiovascular mortality with over 25 years follow-up: A combined analysis of two British cohorts. Environ Int. 2017;99:275-281.

8. Karottki DG, Beko G, Clausen G, et al. Cardiovascular and lung function in relation to outdoor and indoor exposure to fine and ultrafine particulate matter in middle-aged subjects. Environ Int. 2014;73:372-381

9. Lu, F., Xu, D., Cheng, Y., Dong, S., Guo, C., Jiang, X., \& Zheng, X. (2015). Systematic review and metaanalysis of the adverse health effects of ambient PM2. 5 and PM10 pollution in the Chinese population. Environmental research, 136, 196-204.

10. United States Environmental Protection Agency. (2018, June 20). Health and Environmental Effects of Particulate Matter (PM). Retrieved October 2018, from Particulate Matter (PM) Pollution: https://www.epa.gov/pm-pollution/health-and-environmental-effects-particulate-matter-pm 
11. Ackermann-Liebrich, U., Leuenberger, P., Schwartz, J., Schindler, C., Monn, C., Bolognini, G., . . Tsc. (1997). Lung function and long term exposure to air pollutants in Switzerland. Study on Air Pollution and Lung Diseases in Adults (SAPALDIA) Team. American Journal of Respiratory and Critical Care Medicine(155), 122-129.

12. Sekine, K., Shima, M., Nitta, Y., \& Adachi, M. (2004). Long term effects of exposure to automobile exhaust on the pulmonary function of female adults in Tokyo, Japan. Occupational Environmental Medicine, 61(4), 350-357.

13. Offerman, F. J. (2010). IAQ in Airtight Homes. ASHRAE Journal, 52(11), 58-60.

14. Abt, E., Suh, H. H., Catalano, P., \& Koutrakis, P. (2000). Relative contribution of outdoor and indoor particle sources to indoor concentrations. Environmental Science \& Technology, 34, 3579-3587.

15. United States Environmental Protection Agency. (2017, April 12). Technical overview of volatile organic compounds. Retrieved November 2018, from Indoor Air Quality: https://www.epa.gov/indoorair-quality-iaq/technical-overview-volatile-organic-compounds

16. International Agency for Research on Cancer. (2018, November 2). Agents Classified by the IARC Monographs, Volumes 1-123. Retrieved August 2019, from https://monographs.iarc.fr/wpcontent/uploads/2018/09/ClassificationsAlphaOrder.pdf

17. Allen, J. G., MacNaughton, P., Satish, U., Santanam, S., Vallarino, J., \& Spengler, J. D. (2016). Associations of cognitive function scores with carbon dioxide, ventilation and volatile organic compound exposures in office workers: a controlled exposure study of green and conventional office environments. Environmental Health Perspectives, 124(6), 805-812.

18. Delgado-Saborit, J. M., Aquilina, N. J., Meddings, C., Baker, S., \& Harrison, R. M. (2011). Relationship of personal exposure to volatile organic compounds to home, work and fixed site outdoor concentrations. Science of the Total Environment, 409, 478-488.

19. Agency for Toxic Substances \& Disease Registry. (2020, June). Minimal Risk Levels (MRLs) List. Retrieved September 2019, from Minimal Risk Levels (MRLs) for Hazardous Substances: https://www.atsdr.cdc.gov/mrls/mrllist.asp

20. Tsai, D. H., Lin, J. S., \& Chan, C. C. (2012). Office workers' sick building syndrome and indoor carbon dioxide concentrations. J Occup Environ Hyg, 9(5), 345-51.

\section{Figures}




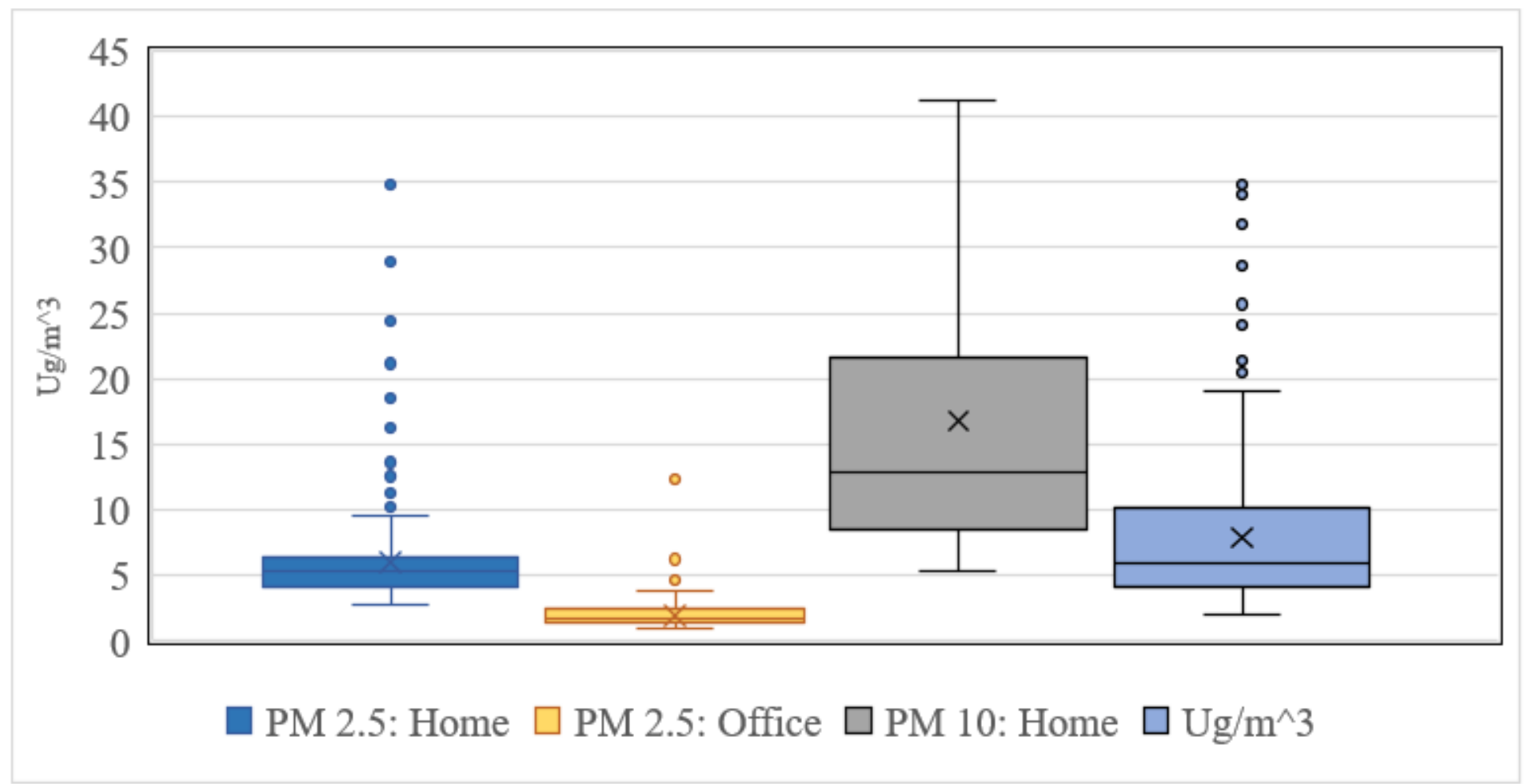

Figure 1

Comparison of PM2.5 $(\mu \mathrm{g} / \mathrm{m} 3)$ and PM10 $(\mu \mathrm{g} / \mathrm{m} 3)$ levels and variability between office locations 


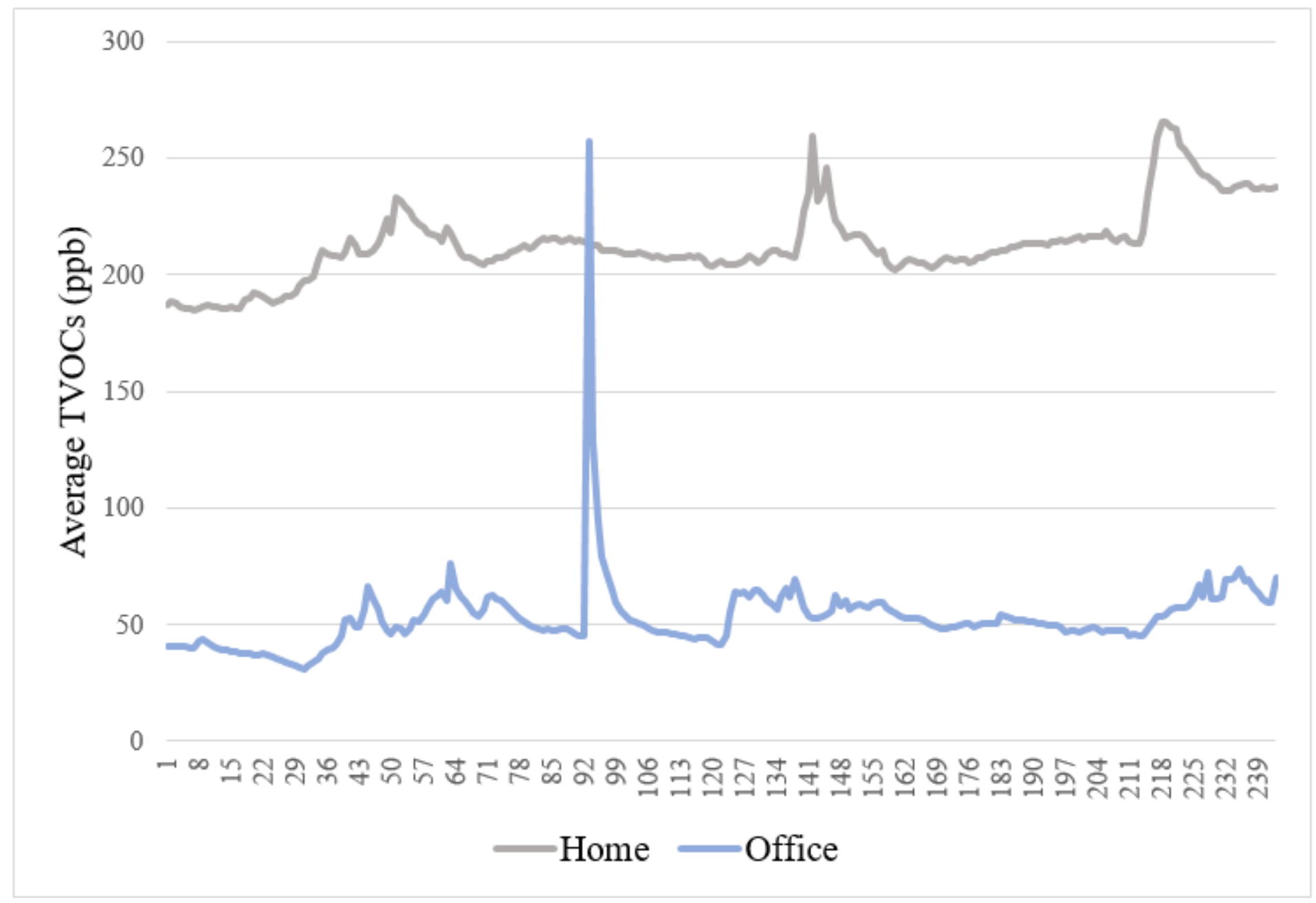

Figure 2

Continuous graph of mean TVOC levels throughout the course of the research timeline 